\title{
Evaluation of Drought Tolerance Selection Indices in Chickpea Genotypes
}

\author{
Uday Chand $\mathrm{Jha}^{{ }^{*}}$, Parthasarathi Basu ${ }^{1}$, Sandip Shil ${ }^{2}$ and Narendra Pratap Singh ${ }^{1}$ \\ ${ }^{1}$ Indian Institute of Pulses Research, Kanpur, Uttar Pradesh (208 024), India \\ ${ }^{2}$ Central Plantation Crops Research Institute, Research Center, Mohitnagar, Jalpaiguri, West Bengal (735 102), India
}

\section{Article History}

Manuscript No. AR1696a

Received in $20^{\text {th }}$ September, 2016

Received in revised form $16^{\text {th }}$ November, 2016

Accepted in final form 30 ${ }^{\text {th }}$ November, 2016

\section{Correspondence to}

*E-mail: uday_gene@yahoo.co.in

\section{Keywords}

Drought, genotype, selection indices, PCA, cluster analysis

\begin{abstract}
Drought or soil moisture stressremains one of the most important abiotic stresses; limiting chickpea yield worldwide. In order to identify drought tolerant chickpea genotype, 34 genotypes (13 desi and 21 kabuli including 4 checks) were evaluated under irrigated and moisture stressed condition in randomized complete block design (RBD) with three replications during 2013-14. Six drought tolerance indices viz, mean productivity (MP), geometric mean productivity (GMP), yield index (YI), tolerance index (TOL), stress susceptibility index (SSI), and superiority measures (SM) were implicated on the basis of grain yield in moisture stress $\left(\mathrm{Y}_{\mathrm{s}}\right)$ and well irrigated $\left(\mathrm{Y}_{\mathrm{p}}\right.$ ) conditions. Genotypes viz. FLIP03-100, FLIP05-123C, FLIP0398C, IPC2009-102 and IPC2009-186 were found to be superiorgenotypes based on MP and GMP drought tolerant indices under moisture stress condition. High significant positive correlations were recorded between MP and GMP $\left(0.944^{* *}\right)$, MP and YI $\left(0.984^{* *}\right)$, TOL and SSI $\left(0.877^{* *}\right)$ and GMP and YI $\left(0.984^{* *}\right)$ indices. Principal component analysis lowered the six indices into two components first and second component justifying $97.9 \%$ of the variations $(84.63$ and $13.34 \%$ for PC1 and PC2, respectively). Further, the genotypes were grouped into 4 groups by two ways cluster analysis (using Ward's method) based on $Y_{p}, Y_{s}$ and drought tolerance indices. Importantly, the results of correlation, 3D graphs, bi-plot and cluster analysis reveals that the most suitable indices to screen chickpea genotypes in drought stress conditions were MP, GMP and YI. Therefore, these indices may be useful for selection of drought tolerant chickpea genotypes.
\end{abstract}

\section{Introduction}

Drought stress remains one of the major abiotic stresses adversely affecting plant growth and causes serious yield challenge in crops across the globe (Tuberosa, 2102).Given the current adversely changing global climate and increasing pressure of human population growth predicted to be 9 billion by 2050 (Godfray et al., 2010), drought stress can further aggravate the global food security. Chickpea remains the second most important grain legume after common bean; playing crucial role in contributing protein based dietary energy to the human population across the globe (Varshney et al. 2013). Importantly, $80 \%$ of the global chickpea production is received from Southern and South-Eastern Asia (Gaur et al., 2012). India remains the top chickpea producing country across the globe (FAO, 2013). Global production of chickpea is recorded to be $14.2 \mathrm{mt}$ from $14.8 \mathrm{mha}$ areas with productivity of $0.96 \mathrm{t} \mathrm{ha}^{-1}$ (FAO, 2014). Importantly, $90 \%$ of chickpea are grown in rainfed condition (Kumar and Abbo, 2001) where drought stress limits chickpea productivity (Toker et al., 2007;
Kashiwagi et al., 2013). The yield losses due to abiotic stresses may exceed $(6.4 \mathrm{mt})$ those caused by biotic stresses $(4.8 \mathrm{mt})$ (Ryan, 1997). Drought/heat incurred economic losses of 1.3 billion US \$ in chickpea assessed by (Ryan, 1997). Notably, global demand of chickpea will increase from current 14.2 $\mathrm{mt}$ to $18.3 \mathrm{mt}$ by 2050 (Nedumaran and Bantilan, 2013). Considering drought stress, it causes yield loss up to $50 \%$ in chickpea (Sabaghpour et al., 2006). Therefore, to sustain the global chickpea production under adversely changing climate; it urgently necessitates strengthening of genetic resource coupledwith effective selection criteria for drought tolerance in chickpea. In order to select drought tolerant chickpea, we assessed selection indices for drought tolerance in 34 chickpea genotypes including 4 checks under irrigated and rainfed condition.

\section{Materials and Methods}

The present study was conducted at Indian Institute of Pulses Research (IIPR), Kanpur. The experimental material 
constituted 34 chickpea genotypes obtained from ICARDA and IIPR. The experiment was conducted in the year 2012-13 under contrasting condition of moisture stress and irrigated condition in RBD with three replications. Each genotype was sown in two rows having $4 \times 0.3 \mathrm{~m}^{2}$ plot size. Crop was grown in accordance with the recommended package of practices under both conditions. Grain yield data was recorded from 10 randomly selected plants for each genotype under both conditions. Additionally, data on days to first flowering, days to $50 \%$ flowering, days to maturity, leaf area index (LAI), cell membrane stability (CMS), seeds pod ${ }^{-1}, 100$ seed weight and plot yield was recorded.

Six drought tolerance indices including Geometric mean productivity (GMP), yield index (YI), mean productivity (MP), Stress susceptibility index (SSI), Tolerance index (TOL), Superiority measure (SM) were estimated by the following formula:

Geometric mean productivity $(\mathrm{GMP})=\mathrm{Yp}_{\mathrm{i}} \times \mathrm{Ys}_{\mathrm{i}}($ Fernandez 1992)

Yield index (YI)=Ys $/$ Ys (Gavuzzi et al., 1997; Lin et al., 1986)
Mean productivity $(\mathrm{MP})=\left(\mathrm{Yp}_{\mathrm{i}}+\mathrm{Ys}_{\mathrm{i}}\right) / 2$ (Rosielle and Hamblin, 1981)

Stress susceptibility index $(\mathrm{SSI})=\left(1-\left(\mathrm{Ys}_{\mathrm{i}} / \mathrm{Yp}_{\mathrm{i}}\right)\right) / \mathrm{SI}($ Fischer and Maurer, 1978)

Tolerance index $(\mathrm{TOL})=\mathrm{Yp}_{\mathrm{i}}-\mathrm{Ys}_{\mathrm{i}}$

$\mathrm{Ys}_{i}$ and $\mathrm{Yp}_{i}$ are the grain yield of genotypes in water stress and well watered condition; SI is stress intensity, where SI=1$(\mathrm{Ys} / \mathrm{Yp})$; Ys=total grain yield mean in stress condition; $\mathrm{Yp}=$ total grain yield mean in normal condition.

\section{Results and Discussion}

\subsection{Genetic variability}

Analysis of variance showed significant genetic variability for the under taken traits not shown here. The genotypes FLIP03-100, FLIP05-123C, FLIP03-98C, IPC2009-102 and IPC2009-186 showed significant higher value for MP and YI drought tolerant indices in comparison to the checks JGK1and ICC4958 given in Table 1. This result was in agreement with the result obtained by Yucel and Mart (2014).

\begin{tabular}{|c|c|c|c|c|c|c|c|c|c|}
\hline Id & genotype & YS & YP & GMP & YI & MP & SSI & TOL & SM \\
\hline 1. & FLIP06-72 & 131.67 & 246.67 & 180.22 & 0.01 & 189.17 & 6.76 & 115 & 8.68 \\
\hline 2. & FLIP05-172C & 258.33 & 361.67 & 305.66 & 0.02 & 310 & 4.14 & 103.33 & 14.22 \\
\hline 3. & FLIP06-12C & 231.67 & 276.67 & 253.17 & 0.02 & 254.17 & 2.36 & 45 & 62.35 \\
\hline 4. & ILC3279 & 101.67 & 195 & 140.8 & 0.01 & 148.33 & 6.94 & 93.33 & 20.06 \\
\hline 5. & FLIP06-59C & 61.67 & 186.67 & 107.29 & 0.01 & 124.17 & 9.7 & 125 & 5.01 \\
\hline 6. & FLIP03-127C & 276.67 & 305 & 290.49 & 0.02 & 290.83 & 1.35 & 28.33 & 82.35 \\
\hline 7. & FLIP05-123C & 370 & 381.67 & 375.79 & 0.03 & 375.83 & 0.44 & 11.67 & 105.12 \\
\hline 8. & FLIP05-56C & 258.33 & 415 & 327.43 & 0.02 & 336.67 & 5.47 & 156.67 & 0 \\
\hline 9. & FLIP06-56C & 268.33 & 298.33 & 282.94 & 0.02 & 283.33 & 1.46 & 30 & 80.22 \\
\hline 10. & FLIP03-98C & 411.67 & 380 & 395.52 & 0.03 & 395.83 & -1.21 & -31.67 & 177.35 \\
\hline 11. & FLIP06-26C & 246.67 & 248.33 & 247.5 & 0.02 & 247.5 & 0.1 & 1.67 & 120.13 \\
\hline 12. & FLIP03-59C & 121.67 & 128.33 & 124.96 & 0.01 & 125 & 0.75 & 6.67 & 112.5 \\
\hline 13. & FLIP05-18C & 300 & 303.33 & 301.66 & 0.02 & 301.67 & 0.16 & 3.33 & 117.56 \\
\hline 14. & FLIP05-154C & 216.67 & 270 & 241.87 & 0.02 & 243.33 & 2.86 & 53.33 & 53.39 \\
\hline 15. & FLIP06-44C & 390 & 398.33 & 394.14 & 0.03 & 394.17 & 0.3 & 8.33 & 110.01 \\
\hline 16. & FLIP05-51C & 376.67 & 386.67 & 381.63 & 0.03 & 381.67 & 0.37 & 10 & 107.56 \\
\hline 17. & FLIP09-81C & 190 & 220 & 204.45 & 0.02 & 205 & 1.98 & 30 & 80.22 \\
\hline 18. & IPC09-35 & 485 & 490 & 487.49 & 0.04 & 487.5 & 0.15 & 5 & 115.01 \\
\hline 19. & IPC09-186 & 833.33 & 670 & 747.22 & 0.07 & 751.67 & -3.53 & -163.33 & 512 \\
\hline 20. & IPC09-161 & 728.33 & 665 & 695.95 & 0.06 & 696.67 & -1.38 & -63.33 & 242 \\
\hline 21. & ICC1882 & 516.67 & 541.67 & 529.02 & 0.04 & 529.17 & 0.67 & 25 & 86.68 \\
\hline 22. & ICC4958(CH) & 550 & 553.33 & 551.66 & 0.05 & 551.67 & 0.09 & 3.33 & 117.56 \\
\hline 23. & ICC92944(CH) & 740 & 743.33 & 741.66 & 0.06 & 741.67 & 0.06 & 3.33 & 117.56 \\
\hline
\end{tabular}




\begin{tabular}{llcccccccc}
\hline & & \multicolumn{1}{c}{} & & & & & & \\
\hline Id & genotype & YS & YP & GMP & YI & MP & SSI & TOL & SM \\
\hline 24. & JGK1(CH) & 315 & 348.33 & 331.25 & 0.03 & 331.67 & 1.39 & 33.33 & 76.06 \\
25. & GG2 & 635 & 630 & 632.5 & 0.05 & 632.5 & -0.12 & -5 & 130.68 \\
26. & ICCV07110 & 268.33 & 298.33 & 282.94 & 0.02 & 283.33 & 1.46 & 30 & 80.22 \\
27. & RSG888(CH) & 841.67 & 863.33 & 852.43 & 0.07 & 852.5 & 0.36 & 21.67 & 91.13 \\
28. & ILC72 & 96.67 & 165 & 126.29 & 0.01 & 130.83 & 6 & 68.33 & 39.01 \\
29. & ILC1929 & 190 & 220 & 204.45 & 0.02 & 205 & 1.98 & 30 & 80.22 \\
30. & ILC2555 & 278.33 & 285 & 281.65 & 0.02 & 281.67 & 0.34 & 6.67 & 112.5 \\
31. & ILC195 & 73 & 128.33 & 96.79 & 0.01 & 100.67 & 6.25 & 55.33 & 51.34 \\
32. & FLIP93-93C & 131.67 & 180 & 153.95 & 0.01 & 155.83 & 3.89 & 48.33 & 58.68 \\
33. & FLIP03-100C & 423.33 & 428.33 & 425.83 & 0.03 & 425.83 & 0.17 & 5 & 115.01 \\
34. & IPC09-102 & 783.33 & 786.67 & 785 & 0.06 & 785 & 0.06 & 3.33 & 117.56 \\
\hline
\end{tabular}

\subsection{Correlation analysis}

Correlation between drought tolerance indices and grain yield under both water stress and irrigated condition has been given in Table 2. Indices those showed high correlation with grain yield under both environments had been selected as best one and deployed to select genotypes having high yield under both condition. MP, GMP and YI indices showed significant positive and high correlation with grain yield under both condition. Considering this, the genotypes showed high value for these indices were reported to be most tolerant. Results of positive correlation between GMP and MP were in agreement with the result obtained in maize (Parihar et al., 2012), durum wheat (Ahmadizadeh et al., 2012; Drikvand et al., 2012). While, SSI index showed highly significant negative correlation with Yp, Ys, GMP, GP, and SM. Likewise, TOL showed significant positive correlation with all the indices except SSI. Similarly, Sabaghina and Janmohammadi (2014) reported significant positive correlation between SSI and TOL under moisture stress condition. While, SM showed positive correlation with all undertaken indices except SSI and TOL.

\begin{tabular}{|c|c|c|c|c|c|c|c|c|}
\hline & YS & YP & GMP & YI & MP & SSI & TOL & SM \\
\hline YS & 1 & & & & & & & \\
\hline YP & $0.977^{* *}$ & 1 & & & & & & \\
\hline GMP & $0.996^{* *}$ & $0.992^{* *}$ & 1 & & & & & \\
\hline YI & $0.989^{* *}$ & $0.966^{* *}$ & $0.944^{* *}$ & 1 & & & & \\
\hline MP & $0.995^{* *}$ & $0.993^{* *}$ & $1^{* *}$ & 0.984 & 1 & & & \\
\hline SSI & $-0.719^{* *}$ & $-0.587^{* *}$ & $-0.671^{* *}$ & $-0.681^{* *}$ & $-0.662^{* *}$ & 1 & & \\
\hline TOL & $-0.657^{* *}$ & $-0.479^{* *}$ & $-0.585^{* *}$ & $-0.65^{* *}$ & $-0.578^{* *}$ & $0.877^{* *}$ & 1 & \\
\hline SM & $0.636^{* *}$ & $0.476^{* *}$ & $0.567^{* *}$ & $0.64^{* *}$ & $0.566^{* *}$ & $-0.733^{* *}$ & $-0.925^{* *}$ & 1 \\
\hline
\end{tabular}

${ }^{* *}$ Correlation is significant at the 0.01 level (2-tailed)

\subsection{PCA analysis}

PCA analysis was performed using software R version 3.3.1 to work out the relationship among the given genotypes and the undertaken drought tolerance indices. PCA reduced the six indices into 2 components. The horizontal axis was related to first component and the vertical axis was related to the second component. Principal component analysis (PCA) reported the first and secondcomponents justified $97.97 \%$ of the variations between criteria ( 84.63 and $13.34 \%$ for PC1 and PC2, respectively) (Figure 1). The first component explained $84.63 \%$ variation with the TOL, SM and $\mathrm{Y}_{\mathrm{p}}$. While, the second component explained $13.34 \%$ variation with SSI, GMP, MP and Ys. These results are in concordance with the result obtained by Sabaghina and Janmohammadi (2014).

\subsection{Three dimensional plots}

In order to select drought tolerant genotypes three dimensional plots (Ys, Yp, and MP) was depicted. The genotypes were divided into 4 groups and marked with four different colors in Figure 2. This plot can aid in selecting high yielding genotypes under both irrigated and water stress condition. According to three-dimensional plots genotypes (IPC09-102, ICC92944, IPC09-186, and IPC09-161) remained in group1. These 


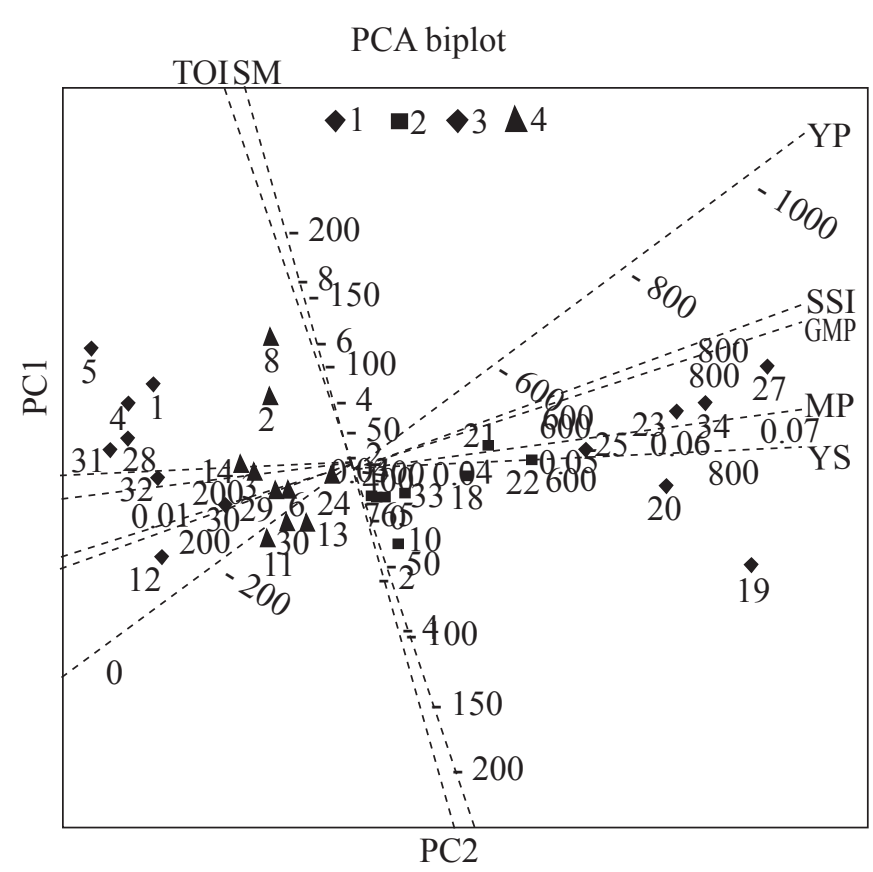

Figure 1: Biplot of 34 chickpea genotypes and 6 drought tolerance indices based on PC1 and PC2

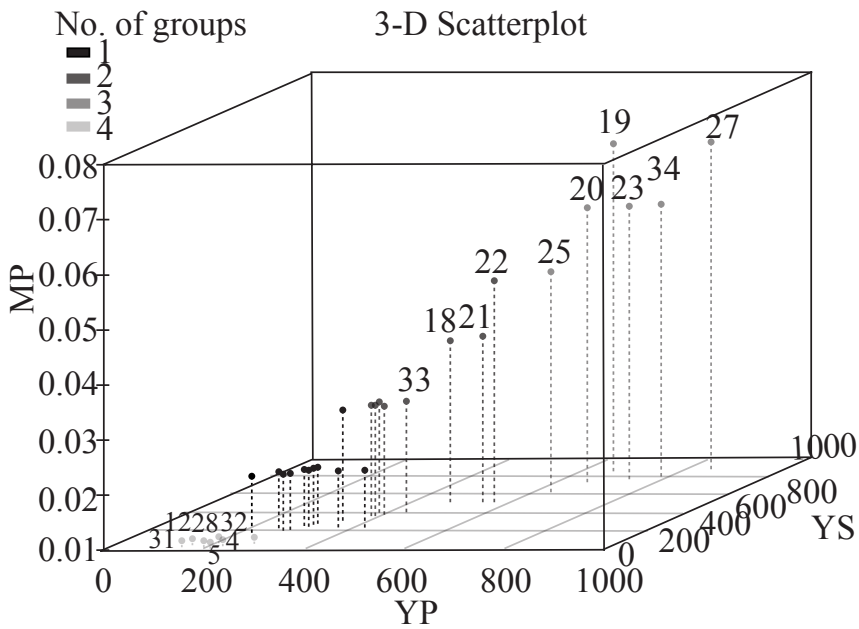

Figure 2: The 3-D plots among the MP, Yp, Ys..

genotypes showed higher yield under both moisture stress and non moisture stress condition. While, genotypes IPC09-35, ICC1882, FLIP03-100C etc. existing in group 2 showed high yield under irrigated condition. The genotypes FLIP05-154C, FLIP06-12C, FLIP05-56C etc. existing in group 3 showed higher yield under moisture stress condition only. Interestingly group 4 containing FLIP93-93C, ILC1929, FLIP03-59C genotypes showed poor yield under both moisture stress and non moisture stress conditions. Similar kinds of results were noted by Parihar et al. (2012) in maize.

\subsection{Cluster analysis}

Two-way cluster analysis via running software $\mathrm{R}$ version 3.3.1 (using Ward's methods) based on Yp, Ys and other quantitative indices of drought tolerance was performed for the given chickpea genotypes. The genotypes were categorized into 4 groups given in Figure 3. The first cluster included 9 genotypes, the second cluster contained 5 genotypes, whereas the third cluster contained 8 and the fourth cluster included 12 genotypes. To this end, considering higher value of GMP and MP value IPC09-102 (785 g), and IPC09-186 (747.2 g) desigenotypesshowed superiority over the check ICC4958 (551.6 g). Similarly, FLIP05-123C (375.7 g) and FLIP03-98C (395.5 g) genotypes outperformed the kabuli check JGK1(331.2 g).These results were in accordance with Color key and histogram Genotype heatmap

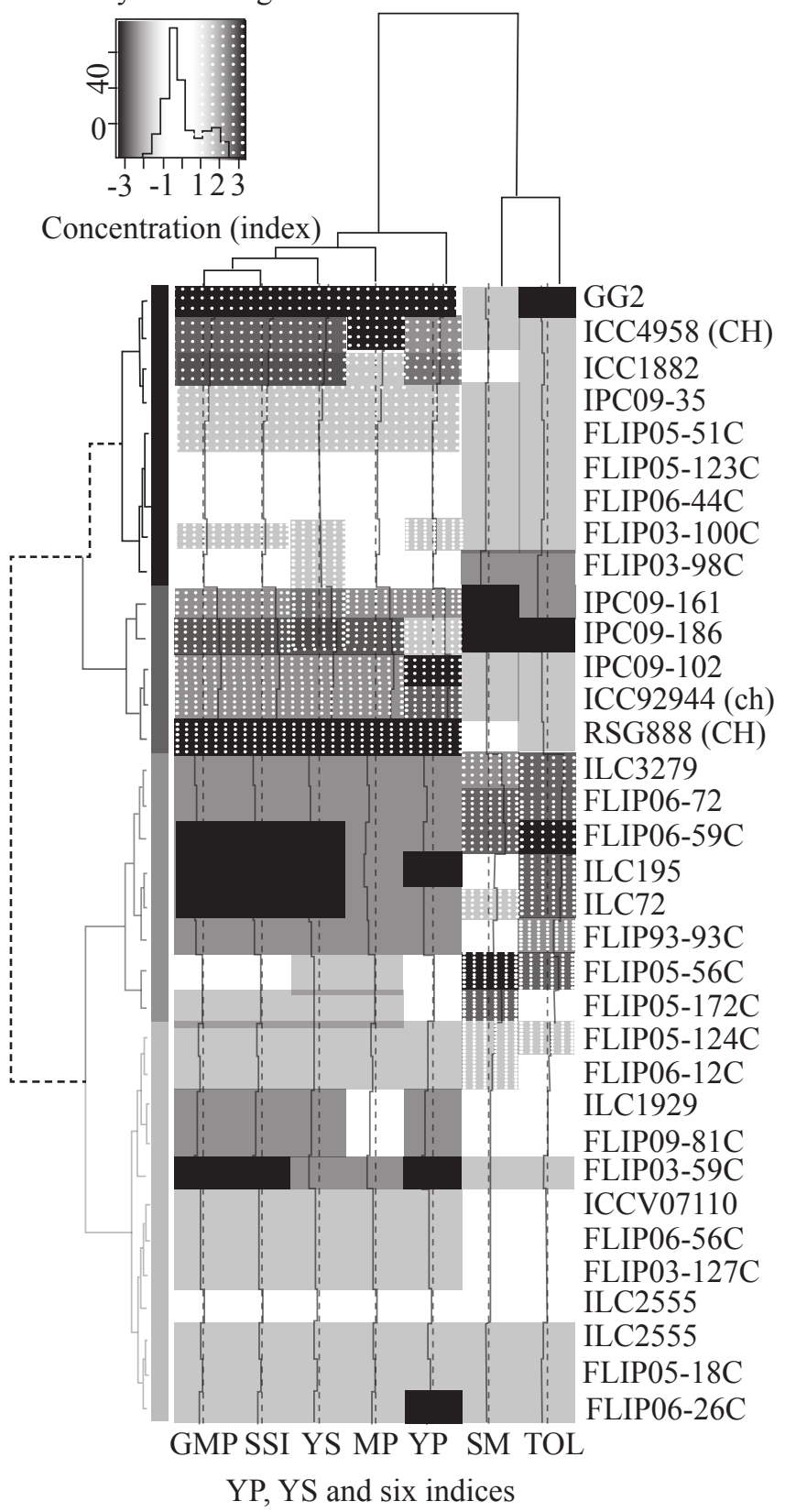

Figure 3: Clustering of chickpea genotypes using ward's method based on Yp, Ys and six indices 
the result recorded by Yucel and Mart (2014). Furthermore, based on the given cluster analysis, distantly related genotypes can be employed in crossing programme for creating genetic variability for drought tolerance in chickpea.

\section{Conclusion}

Exhibited MP, GMP and YI indices could be efficiently employed to screen chickpea genotypes under soil moisture stress. Concomitantly, genotypes viz. FLIP03-100, FLIP05123C, FLIP03-98C, IPC2009-102 and IPC2009-186 were found to be superior in yield performance under drought stress condition. Therefore, these genotypes can be effectively exploited for developing drought tolerant chickpea cultivars.

\section{References}

Ahamadizadeh, M., Valizadeh, M., Shahbazi, H., Nori, A., 2012. Behavior of durum wheat genotypes under normal irrigation and drought stress conditions in the greenhouse. African Journal of Biotechnology 11, 1912-1923.

Drikvand, R., Doosty, B., Hosseinpour, T., 2012. Response of rainfed wheat genotypes to drought stress using drought tolerance indices. Journal of Agriculture Science 4, 126-131.

FAOSTAT, 2014. FAO Statistics Division, Available at: http:// faostat3.fao.org/compare/E (accessed 27.02.16.).

Fernandez, G.C.J., 1992. Effective selection criteria for assessing plant stress tolerance. In: Proceedings of the international symposium on adaptation of vegetable and other food crops in temperature and water stress. Taiwan, 257-270.

Fischer, R.A., Maurer, R., 1978. Drought Resistance in Spring Wheat Cultivars, I. Grain Yield Response, Australian Journal of Agriculture Research 29, 897-912.

Gaur, P.M., Jukanti, A.K., Varshney, R.K., 2012. Impact of genomic technologies on chickpea breeding strategies. Agronomy 2, 199-221.

Gavuzzi, P., Rizza, F., Palumbo, M., Campaline, R.G., Ricciardi, G.L., Borghi, B., 1997. Evaluation of field and laboratory predictors of drought and heat tolerance in winter cereals. Canadian Journal of Plant Science 77, 523-531.

Godfray, H.C., Beddington, J.R., Crute, I.R., Haddad, L., Lawrence, D., Muir, J.F., Pretty, J., Robinson, S., Thomas, S.M., Toulmin, C. 2010. Food security: the challenge of feeding 9 billion people. Science 327, 812-818.

Kashiwagi, J., Krishnamurthy, L., Gaur, P.M., Upadhyaya, H.D., Varshney, R.K., Tobita, S., 2013.Traits of relevance to improve yield under terminal drought stress in chickpea (C. arietinum L.). Field Crops Research 145, 88-95.

Kumar, J., Abbo, S., 2001. Genetics of flowering time in chickpea and its bearing on productivity in semi arid environments. Advances in Agronomy 72, 107-138.

Lin. C.S., Binns, M.R., Lefkovitch, L.P., 1986. Stability analysis: where do we stand? Crop Science 26, 894-900.

Nedumaran, S., Bantilan, M.C.S., 2013. Grain legumes futures under changing socio-economic and climate scenarios. ICRISAT Working Paper Series.

Parihar, A.K., Godawat, S.L., Singh, D., Parihar, C.M., Jat, M.L., 2012. Behaviour of Quality Protein Maize (QPM) genotypes under well irrigated and water stress conditions in subtropical climate. Maydica 57, 293-299.

Rosielle, A.A., Hamblin, J., 1981. Theoretical aspects of selection for yield in stress and non- stress environment. Crop Science 21, 943-946.

Ryan, J.G., 1997. A global perspective on pigeonpea and chickpea sustainableproduction systems: present status and future potential. In: Asthana, A.N., Ali, M. (Eds.), Recent Advantages in Pulses Research. Indian Society of Pulses Research and Development, Indian Institute of Pulses Research, Kanpur, India, 1-31.

Sabaghnia, N., Janmohammadi, M., 2014. Evaluation of Selection Indices for Drought Tolerance in some Chickpea (Cicer arietinum L.) Genotypes. Acta Technologica Agricultuarae. DOI: 10.2478/ata-20140002 .

Sabaghpour, S.H., Mahmodi, A.A., Kamel, S.M., Malhotra, R.S., 2006. Study onchickpea drought tolerance lines under dryland condition of Iran. Indian Journal of Crop Science, 1, 70-73.

Toker, C., Lluch, C., Tejera, N.A., Serraj R., Siddique, K.H.M., 2007a. Abiotic stress. In: Yadav, S.S., Redden, R., Chen, W., Sharma, B., (eds), Chickpea Breeding and Management, 474-496. CAB International, UK.

Tuberosa, R., 2012. Phenotyping for drought tolerance of crops in the genomics era. Frontier in Plant Physiology 3, 347.

Varshney, R.K., Gaur, P.M., Chamrathi, S.K., Krishnamurthy, L., Tripathi, S., Kashiwagi, J., Singh, V.K., Thudi, M., Jaganathan, D., 2013. Fast-track introgression of "QTLhotspot" for root traits and other drought tolerance trait in JG 11, an elite and leading variety of chickpea (Cicer arietinum L.). The Plant Genome 6, 1-26.

Yucel, D., Mart, D., 2014. Drought tolerance in chickpea (Cicer arietinum L.) genotypes. Turkish Journal of Agricultural and Natural Sciences 1, 1299-1303. 